\title{
Is the safety safe: the experience of distance education (or self-isolation)
}

\author{
Ekaterina A. Samorodova - Irina G. Belyaeva - Daria S. Bylieva \\ - Alfred Nordmann
}

DOI: 10.18355/XL.2022.15.01.01

\begin{abstract}
Education and safety? The authors of this study set out to answer this difficult question, relying on the experience of working in remote access during the coronavirus pandemic, The aim is to understand whether the humanitarian project might be endangered be the desire to make life absolutely safe, and to identify the extent of the appropriate safety measures that prevent the spread of the coronavirus and preserve a safe space for the formation of an educated personality. In the course of the study, the authors found that by focusing on one urgent danger, there is a possibility of neglecting others, no less important. The success of solving the problem of ensuring security in the face of an unexpected pandemic by transitioning to remote technologies does not signify that this solution is actually the best. The need to preserve education as a resource that supports the security of human existence constrains the ways in which the established forms of the educational system can be transformed. Changing the format of education leads to other changes in society, which may include many negative consequences. While short-term consequences are already noticeable, coupled with the concern how long-term consequences will affect the further development of society. If the safety and security of societies requires a high level of education, the preservation of the educational system is an important safety factor alongside protection from the pandemic. The paper therefore investigates also the attitudes of students in this ambivalent situation.
\end{abstract}

Key words: safety, distance education, self-isolation, safe learning, safe education

\section{Introduction}

As opposed to training, instruction, or military drill, education refers to a process by which individuals and social groups learn to develop their talents, acquire capabilities, and become self-sufficient in some area of expertise. It does not require elaborate theories of Bildung (Humboldt, 2000) to know that the educational process needs to provide safe spaces in which learners can fearlessly try themselves out and learn from mistakes. The COVID-19 pandemic has challenged teachers and students, politicians and public administrators to preserve and protect these safe spaces, answering the question what defines them and what are the necessary and sufficient conditions to maintain them. Having witnessed the various responses to this question and investigated the attitudes of students, we arrive at the paradoxical result that the best efforts to shield and protect the educational process may also undermine it.

The paradox itself is familiar enough from discussions of safety and security. The distinction between these two concepts is well established (Nordmann \& Ripper, 2019 ). "Safety" concerns the safe operation of technical devices of all kinds protecting people from technologies, procedures, and processes: Does the operation of a power plant or an airplane pose a threat to the well-being of users or citizens, and is there for example, a danger to human health emanating from the device itself? "Security" concerns the question whether technical and other processes are in good hands - protecting technologies and ourselves from human failures: Is the operation of a potentially dangerous or toxic technology properly regulated and is it protected, for example, against sabotage or terrorism? Concretely, when one asks someone whether they feel safe where they live, they might answer that they feel safe because they have

XLinguae, Volume 15 Issue 1, January 2022, ISSN 1337-8384, eISSN 2453-711X 
many locks and chains on their apartment door (technical safety), but they might also answer that they feel safe because they are unafraid to go out at night and walk the streets (public security). And when one asks in the pandemic whether there is safe space for the educational process, one answer is that it is safe because there is no personal contact among students (physical safety) or that it is safe because students can present themselves and try things out in group interactions, critical discussions, personal meetings (secure environment).

With these notions of safety and security at hand, one will find that physical safety is necessary for the educational process but that is it not sufficient to maintain the social setting in which students can fearlessly learn from their mistakes, try out new ideas, and publicly demonstrate their skills. Indeed, the need to separate students may enhance their feeling of safety while instilling deep insecurity about the value and worth of their education. This amounts to a feeling of ambivalence which is the subject of the following discussion.

At the dawn of human life, the safety of society was based primarily on its physical protection from the effects of external factors: natural disasters, diseases, wars, etc. International security results from intercultural ties between societies and the creation of protected platforms for intercultural multilateral communication. Within each sovereign state, a system of safe functioning of the branches of government has been built, which ensures a decent life, including an educational system, and feeling of security for the citizens of this state (Vorotnikova \& Karlin, 2021).

During the pandemic, the sovereign states faced the challenge to guarantee the physical safety of the educational process in new ways. Education is, on the one hand, a fairly conservative social institution. On the other hand, the spread of information and communication technologies affects not only the form of teaching, but also the essence of education, which is closely related to the concept of knowledge. In the pandemic, these new technologies became prominent not primarily for new educational concepts and approaches, but for permitting online instruction.

During the "Spanish flu" pandemic in the 1920s, the means of remote interaction were much less diverse than they are today. Telephone, telegraph, and "snail mail" were not widely available to every person and were not fully "contactless," and therefore safe by pandemic standards. During the plague pandemic of the 14th century, there were no contactless means of transferring information between people, in this regard, it was almost impossible to comply with safety measures when transferring information. Thus, the safety of information transfer between people is directly dependent on the level of technical development of society in a specific historical period of time. And for the current situation, there is a question what other means there are to sustain the educational process without using technologies to produce a complete physical separation.

On the other hand, one might argue that in the period of globalization self-isolation has become impossible. Since informational globalization makes it possible to communicate remotely, the process of isolation itself is not what it was and deprives people less than it did in previous centuries. Even before the pandemic, the ability to communicate with people on the other end of the globe without leaving the apartment has changed the role and importance of face-to-face communication. In this regard, it can be argued that our contemporaries are more prepared for self-isolation than our ancestors in previous pandemics. But even if the importance of „face-to-face“ has diminished for communication, it is an open question whether it has diminished for education. The answer to this question depends on what more there is to education than the communicative transfer of information.

Jakubik's research shows that education can be understood as a role, as a place, and as a social community (Jakubik, 2021). As for role and place, one of the most common concepts is the idea of education as transfer of knowledge. Hager and Hodkinson write that 'transfer and the closely connected idea of acquisition are amongst the 
commonest metaphors employed in thought and talk about learning' (Hager, Hodkinson, 2009). Within the framework of representational rendering, knowledge is singled out as a certain entity separate from the world, capable of moving, the world is divided into the "ontologically disjunct domains of words and things" (Spenceley, 2006: 137). As for education understood as social community, Barnett considers the goal of education to be advancing public understanding in the world (Barnett, 2011). Auxier emphasizes the development of the ability to explore, experience, and interpret the world and develop their own perceptions and judgments about the world (Auxier, 2018). Acton believes that the University's pace, and its use, benefits, purpose and effects are formed through interaction with living and non-living entities (Acton, 2017). Actor-network theory based on interconnectedness considers educational practices as spatialized knowledge-building (Edwards, Clarke, 2002, p. 157), where socialities, textualities and materialities are microsites of knowledge (Mulcahy, 2013). The 'transfer' of knowledge thus occurs through material objects (e.g. texts, technologies, artefacts, architectures, bodies) and materializing processes (e.g. embodied encounters, space and place) (Mulcahy, 2013). Thus, knowledge turns out to be inseparable from the world and existence in it. Dovey and Fisher argue that emergent potential the learning cluster imparts the flows of life, people, materials and ideas, where at once social and spatial connections are critical (Dovey \& Fisher, 2014).

Utilizing information and communication technologies primarily to assure the physical distance and safety of students during the pandemic, produces a dramatic decrease of the role of the "world" in education. Spatially separated students and teachers do not even share their experience time when the widely supported asynchronous teaching mode is adopted (Daniel, 2020). Just like the virtual past times of many students, learning becomes dissociated from social reality which is deeply problematic if education serves to shape personality (Krasnoshchekov et al., 2019; Baranova et al., 2021).

As a safety-measure E-learning turns out to be able to solve the problem of survival, but its acceptance has the potential to undermine the socialization of students (Almazova et al. 2020; Baranova, Kobicheva \& Tokareva, 2021; Pokrovskaia et al., 2021; Valieva, Fomina, \& Nilova, 2021; Merkish, 2020).

The goal of this article is to identify how the safety measures preventing the spread of coronavirus affect the formation of an educated personality, whether the protection from infection amounts to sacrificing education: Does the safe space for the educational process afford students the security to take risks, to engage with each other, and to promote faith in the quality of education? This goal is achieved by solving the following research tasks, namely to identify

what are the criteria for choosing / not choosing a distance learning format.

How does the distance format justify the goals of a safe learning format from the point of view of educational process/organization;

How justified / safe are distance learning measures from the perspective of acquiring new knowledge;

How safe are distance learning measures for the development / formation of the student's personality and his interaction with the surrounding society.

\section{Literature review}

The impact of the coronavirus pandemic on the formation process is considered in many issues. The authors analyze the main consequences and difficulties of "selfisolation" Schools have closed in many countries and regions of the world - more than a billion students were left without schooling (Eringfeld, 2021).

Many works are devoted to the problem of the lack of access of a large number of students to distance learning, due to poor communication, lack of the necessary

XLinguae, Volume 15 Issue 1, January 2022, ISSN 1337-8384, eISSN 2453-711X 
technical means for the implementation of training (Dubey, Pushkar \& Pandey, Deepak, 2020). And interaction between teacher and student in distance learning (Huang, Tlili, \& Chang, 2020; Lorente, Arrabal, \& Pulido-Montes, 2020). Distance learning has led to the emergence of complex mental disorders, both students and teachers (Soni, 2020), as well as psychological consequences, in particular, a decrease in the ability to take responsibility for oneself, to understand causal relationships between actions and their consequences and to accept these consequences as a natural result of their own decisions and choices (Pokrovskaia, \& Tyulin, 2021).

The authors of the article would like to draw attention to the fact that the security measures taken to save mankind from infection with the coronavirus may be fraught with no less danger, which may manifest itself a little later, after the end of the pandemic. As noted by all researchers, the forced "self-isolation" negatively affected the quality and outcome of training.

Nevertheless, many researchers today write about a 'new normal' in education (Corvin et al., 2021; Orchard et al., 2021), which means that a return to the educational system before the pandemic impossible. But what exactly does "new" "new" mean, that "institutionalizing and normalizing the actions taken under the outbreak", as they write (Yang, Huang, 2021, Tesar, 2020) or "meaningful societal change through democratic ideals" (Harris \& Santilli, 2020: 126). As noted by Accioly \& Macedo (2021), a microscopic lifeform has not created a "new normal". "New normal" in education is created a new on an already existing basis, taking into account the current conditions. The latter mean not only direct spatial limitations, intensification of fear and anxiety, post-truth epistemological climate (Peters et al., 2020), but all the variety of existing social, environmental and other problems that need to be addressed. Jimmy Jaldemark suggests not to divide the educational environment into biological, geographical, learning, online, offline, and social - but instead use a holistic worldview (Jandric et al., 2020).

\section{Materials, methods and research results}

During training during "self-isolation" during the coronavirus pandemic, training was carried out remotely.

Any learning process (also distance learning) is aimed at obtaining the necessary knowledge and, as I. Kant said, the purpose of knowledge is to serve the moral improvement of a person. Accordingly, all scientific achievements in any of the scientific fields: technical, natural, humanitarian are used for good.

Virtual Internet is a reality, or a new communicative or social environment, a "new social society" that exists in addition to the "real" one, was created by man and he must use it correctly and competently. The outbreak of a pandemic at the end of 2020 largely contributed to the speedy digitalization of society. All education systems have moved to electronic format, replacing the classroom and classroom with a screen. "Screen teacher and student", "screen teacher and class", their relationship, the peculiarities of the educational process in the distance formed a new educational reality in order to implement certain tasks: to give or receive an education. To what extent has this form of training justified itself from the standpoint of a safe process?

A study was conducted by the authors of the article. Among students at a distance in some higher educational institutions of Russia, 1000 people were interviewed by choosing the correct answer from those offered in the questionnaire.

Students were required to answer the following questionnaire questions:

1. What is safety in learning for you?

2. What is the most important thing for you in distance learning?

3 . Why do you prefer distance education?

4. Why don't you choose distance education?

The research results showed the following results. 
To the question "What is safety in learning for you?" students' answers were distributed as follows:

Table 1. What is safety in training for you?

\begin{tabular}{|l|l|}
\hline Response & $\mathbf{\%}$ \\
\hline None potential harm for your health during the learning process & $\mathbf{3 4 \%}$ \\
\hline None potential harm for your education during the learning process & $\mathbf{2 6} \%$ \\
\hline $\begin{array}{l}\text { None potential harm in the process of your education for the } \\
\text { development of your social personality }\end{array}$ & $\mathbf{2 5 \%}$ \\
\hline Other & $\mathbf{1 5 \%}$ \\
\hline
\end{tabular}

Figure 1. What is safety in training for you?

What is safety in training for you? \%

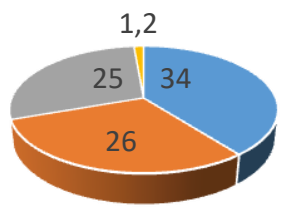

- None potential harm for your health during the learning process

- None potential harm for your education during the learning process

To the question "What is most important for you in distance education?" students had to choose the appropriate answer from the following:

Table 2. What is most important to you in distance education?

\begin{tabular}{|l|l|}
\hline Response & $\%$ \\
\hline Safety & $40 \%$ \\
\hline Convenience & $36 \%$ \\
\hline Quality of education & $14 \%$ \\
\hline Other & $10 \%$ \\
\hline
\end{tabular}

Figure 2. What is most important to you in distance education?

What is most important to you in distance education? \%

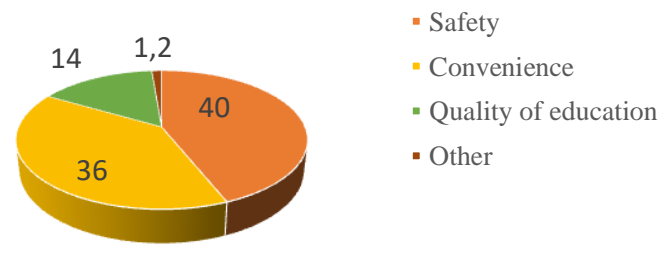


To the question "Why do you prefer distance education?" the students' answers to the questions were distributed as follows:

Table 3.

\begin{tabular}{|l|l|}
\hline Responses & $\mathbf{\%}$ \\
\hline Feel safe as you do not need to leave home and contact people & $\mathbf{2 0} \%$ \\
\hline $\begin{array}{l}\text { You do not like to communicate with people in general and } \\
\text { this form of training suits you perfectly / You feel better in a } \\
\text { virtual classroom / you are used to this form and face-to-face } \\
\text { training does not suit you }\end{array}$ & $\mathbf{9 \%}$ \\
\hline $\begin{array}{l}\text { It is easier for you to pass exams, answer the teacher's } \\
\text { questions during tests, as well as in lessons, because behind } \\
\text { the screen you feel your security and self-confidence }\end{array}$ & $\mathbf{1 2 \%}$ \\
\hline $\begin{array}{l}\text { You learn the material more easily, because the atmosphere of } \\
\text { live communication interferes with you, confuses you and } \\
\text { hinders the development of new knowledge }\end{array}$ & $\mathbf{1 2 \%}$ \\
\hline $\begin{array}{l}\text { You can control the educational process yourself and prefer to } \\
\text { work independently }\end{array}$ & $\mathbf{1 2 \%}$ \\
\hline $\begin{array}{l}\text { You think that the distance format improves the quality of } \\
\text { education, since both the teacher and the trainees are focused } \\
\text { on the educational process and are not distracted by external } \\
\text { factors }\end{array}$ & $\mathbf{8 \%}$ \\
\hline $\begin{array}{l}\text { You enjoy working from home as you don't have to go to } \\
\text { college and spend a lot of time commuting }\end{array}$ & $\mathbf{1 7 \%}$ \\
\hline Other & $\mathbf{1 0 \%}$ \\
\hline
\end{tabular}

Figure 3. Why do you prefer distance education?

Why do you prefer distance education? \%

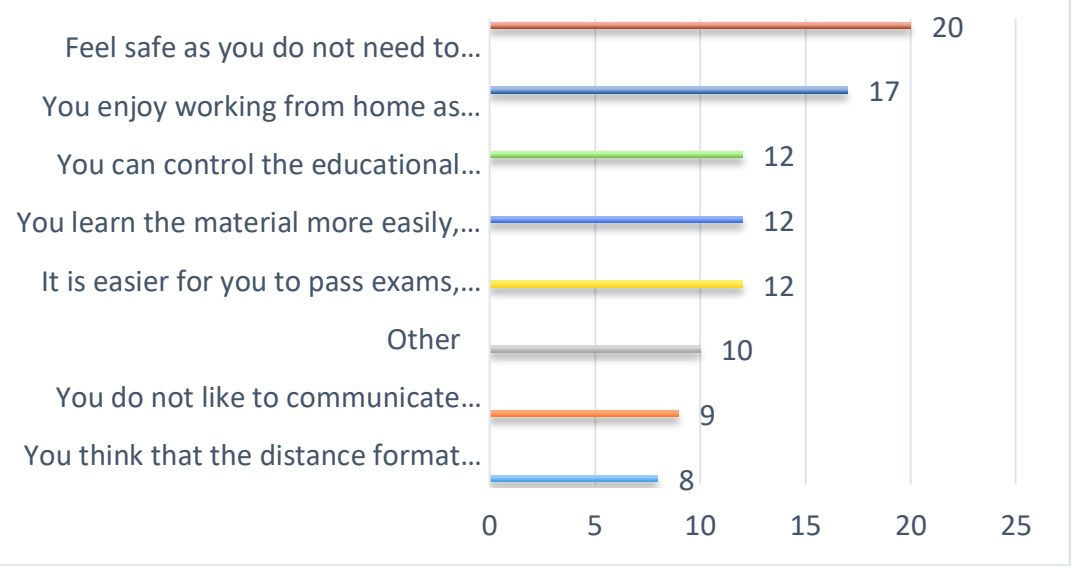

On the fourth research question "Why don't you choose distance education?" received the following responses:

Table 4. Why don't you choose distance education? 


\begin{tabular}{|l|l|}
\hline Responses & $\mathbf{\%}$ \\
\hline $\begin{array}{l}\text { It is difficult for you to communicate with friends and } \\
\text { colleagues in this format }\end{array}$ & $\mathbf{1 0 \%}$ \\
\hline $\begin{array}{l}\text { You are afraid of the screen, it seems unnatural for you to see } \\
\text { faces on the screen and conduct dialogue }\end{array}$ & $\mathbf{1 1 \%}$ \\
\hline $\begin{array}{l}\text { You are missing the direct communication with the teacher that } \\
\text { you need }\end{array}$ & $\mathbf{1 0 \%}$ \\
\hline You feel disconnected from society remotely & $\mathbf{1 9 \%}$ \\
\hline $\begin{array}{l}\text { You feel helpless and lonely if you have difficulty with } \\
\text { connection / Feel fear of a bad connection }\end{array}$ & $\mathbf{2 0 \%}$ \\
\hline $\begin{array}{l}\text { You lose knowledge / You don't learn new material / the quality } \\
\text { of your education decreases }\end{array}$ & $\mathbf{8 \%}$ \\
\hline $\begin{array}{l}\text { You feel in danger of losing yourself/you are afraid of this } \\
\text { format }\end{array}$ & $\mathbf{9 \%}$ \\
\hline You feel in danger of losing others & $\mathbf{1 1 \%}$ \\
\hline Others & $\mathbf{2 \%}$ \\
\hline
\end{tabular}

Figure 4. Why don't you choose distance education?

\section{Why don't you choose distance education?}

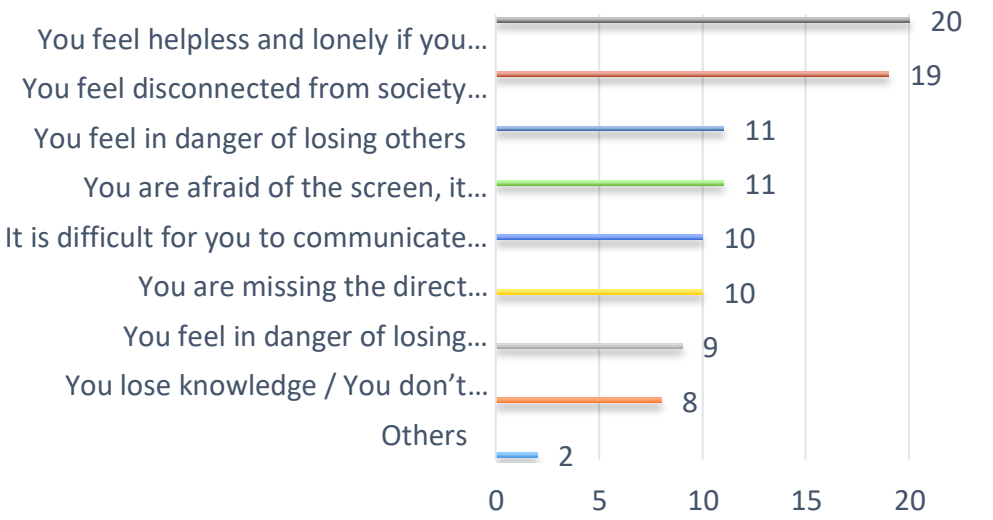

A safe learning experience for most students was the absence of potential harm to health and learning.

A survey of students showed their ambiguous attitude to the learning process in remote access. A large number of participants (40\%) of the survey highlight the criterion of health safety and lack of contact with the outside world as the main advantage of distance learning. Students who find distance education convenient are represented in a slightly smaller number of people (36). Distance education is of high quality for 14 percent of survey participants.

Distance education was chosen by $20 \%$ of students as safe for health, since it is important for these people not to leave their homes, to contact other participants in the educational process. Another group, 17\%, prefers distance education as a convenient form from the point of view of organizing the educational process: there is no need to spend time on the road, but immediately get involved in the educational process. For a minority $(8 \%)$ of the respondents, distance learning is the best option, since it allows

XLinguae, Volume 15 Issue 1, January 2022, ISSN 1337-8384, eISSN 2453-711X 
you to fully and completely concentrate on the studied / taught discipline, in connection with which the quality of education improves. For $12 \%$ of the respondents, distance education is a good option, since this audience can work independently and take responsibility for their education on themselves. An equal number of participants chose distance education, since this format facilitates the passage of midterm control and examination papers, students honor their security by working behind the screen. Also, 12 percent of the survey participants chose the remote form, since the atmosphere of live communication interferes with the perception of new material and is annoying. It should be noted that such a survey was carried out after experience working at a distance, namely during the period of self-isolation measures taken. For $9 \%$ of respondents who prefer not to have contact with a live audience at all, not only due to the pandemic, but distance education is also an ideal format for gaining new knowledge.

To the question "Why don't you choose distance learning?" The answers were also ambiguous.

Most $(20 \%)$ of the respondents do not choose the distance student because this form contributes to a decrease in the level of education. It is difficult for students to communicate with their friends and teachers $(10 \%)$, they lack communication with a teacher in full-time format, but it is necessary $(11 \%)$.

A significant part of the respondents experience psychological difficulties in the remote work format: $19 \%$ of respondents feel fear of being out of touch, feel the danger of poor connection and cannot concentrate on the learning process, $10 \%$ feel lost in space, $9 \%$ feel fear of losing others, $8 \%$ are afraid of losing themselves. For $11 \%$ of participants, seeing their colleagues on the screen is an unnatural and challenging experience.

\section{Conclusion}

The results of the survey allow us to come to the following conclusions. The distance format was chosen by students as a means of maintaining from an organizational standpoint an educational process that is safe for health in the current situation. Remote access avoids close communication between students and increases the chances of not contracting a dangerous disease. This is the most important criterion according to which the majority of students choose the distance type of work.

Nevertheless, the characteristics of the distance process from the standpoint of the quality of education did not find positive responses from the interviewed students. Many of them feel the danger of studying remotely, because they either do not receive the necessary knowledge due to poor communication, or due to psychological phenomena which were mentioned above: fear of the screen, losing oneself, inability to conduct a dialogue with a screen person.

According to a free survey of teachers of several universities in Russia, the level of student achievement in 2020 has sharply decreased by an average of $23 \%$ compared to previous years, and the risk of low-level specialists in the future increased accordingly.

Ensuring safety is important, but by focusing on one immediate hazard, there is a possibility of neglecting others, equally important. The success of solving the problem of providing a sense of safety by transitioning to remote technologies in the face of an unexpected factor like the pandemic does not mean that this actually the best solution. The need to preserve education as a precondition for the security of human existence does not automatically license all changes to the established forms of the educational system, especially if these changes are introduced as the simplest technological solutions to a problem. Although thousands of studies are published today reflecting the greater or lesser success of e-learning during the pandemic, the impact of changing the format of education on personality formation cannot be directly measured using quantitative analysis. The short-term consequences of these changes, 
affecting the methods and forms of teaching and of working with information, are already noticeable today by many practicing teachers. These are coupled with concerns about the ways in which long-term consequences may affect the further development of society. In order to guarantee the safety, security, general well-being and quality of life of any state, societies require highly educated personnel, experts, and specialists whose scientific and practical achievements are the main guarantee of success. Distance education is an important innovation for students and teachers who cannot learn together in a real educational environment, as such it is a big breakthrough in the system of science and education. However, one kind of progress should not interfere with another, even in the name of safety, when it creates a sense of insecurity regarding educational preparedness to master the future.

\section{Bibliographic references}

Accioly I. \& Macedo, D., (2021). Education, Equality and Justice in the New Normal: Global Responses to the Pandemic. Bloomsbury Publishing.

Action, R., (2017). Place-people-practice-process: Using sociomateriality in university physical spaces research. Educational Philosophy and Theory, Vol. 49(14), pp. 1441-1451. https://doi.org/10.1080/00131857.2017.1309637

Almazova, N., Krylova, E., Rubtsova, A. \& Odinokaya, M., (2020). Challenges and Opportunities for Russian Higher Education amid COVID-19: Teachers' Perspective. Education Sciences, Vol. 10(12), 368. https://doi.org/10.3390/educsci10120368

Auxier, R., (2018). The coming revolution in (higher) education: Process, time, and singularity. In A. Stoller \& E. Kramer (Eds.), Contemporary Philosophical Proposals for the University: Toward a Philosophy of Higher Education; Part V: Future Inquiry: Higher Education in the Coming Century. Cham: Springer Nature, 217-260.

Baranova, T., Kobicheva, A. \& Tokareva, E., (2021). Total Transition to Online Learning: Students' and Teachers' Motivation and Attitudes. In D. Bylieva, A. Nordmann, O. Shipunova, \& Volkova, V., (eds.), Knowledge in the Information Society. PCSF 2020, CSIS 2020. Lecture Notes in Networks and Systems, (184), 301310 https://doi.org/10.1007/978-3-030-65857-1_26

Baranova, T.A., Mokhorov, D.A., Kobicheva, A. M. \& Tokareva, E.Y., (2021). The Formation of Students' Personality at Peter the Great St. Petersburg Polytechnic University: Attitude to University and Attitude to Future Profession. European Journal of Contemporary Education. Vol. 10(1), 173-186. https://doi.org/10.13187/ejced.2021.1.173

Barnett, R. (2011). Being a University; Foundations and Futures of Education Series; London: Routledge, Taylor \& Francis Group.

Corvin, J., Naabourg, B., Bularca, S. \& Haile, A., (2021). Approaching a New Normal: Lessons Learned Transitioning Family Education Programming to a Virtual Environment. Health Promotion Practice, 20(10), 152483992110348. https://doi.org/10.1177/15248399211034814

Dovey, K., Fisher, K. (2014). Designing for adaptation: the school as socio-spatial assemblage. The Journal of Architecture, 19(1), 43-63. https://doi.org/10.1080/13602365.2014.882376

Dubey, P. \& Pandey. D., (2020). Distance Learning in Higher Education during Pandemic: Challenges and Opportunities. The International Journal of Indian Psychology, 8(1) 43-46. 10.25215 / 0802.204.

Edwards, R. \& Clarke, J. (2002). Flexible Learning, Spatiality and Identity. Studies in Continuing Education, 24(2), 153-165. https://doi.org/10.1080/0158037022000020965

Eringfeld, S., (2021). Higher education and its post-coronial future: utopian hopes and dystopian fears at Cambridge University during Covid-19. Studies in Higher Education, 46(1), 146-157. https://doi.org/10.1080/03075079.2020.1859681

XLinguae, Volume 15 Issue 1, January 2022, ISSN 1337-8384, eISSN 2453-711X 
Harris, T. \& Santilli, N. R. (2020). Higher education should embrace this luminal moment because there will be no new normal. In Higher education's response to the Covid-19 pandemic: Building a more sustainable and democratic future. Brussels: Council of Europe, 129-136.

Huang, R., Tlili, A., Chang, T.W. et al. (2020). Disrupted classes, undisrupted learning during COVID-19 outbreak in China: application of open educational practices and resources. Smart Learn. Environ 7(19). https://doi.org/10.1186/s40561020-00125-8

Humbolt, W. (2000). Theory of Bildung. In Teaching as a Reflective Practice. The German Didaktik Tradition. New Jersey: Lawrence Erlbaum Associates, 57-61.

Jakubik, M. (2021). Searching for Practical Wisdom in Higher Education with Logos, Pathos and Ethos. Case: Finnish Universities of Sciences. Philosophies 6(3), 63. https://doi.org/10.3390/philosophies6030063

Jandric, P., Jaldemark, J., Hurley, Z., Bartram, B., Matthews, A., Jopling, M. \& Tesar, M., (2020). Philosophy of education in a new key: Who remembers Greta Thunberg? Education and environment after the coronavirus. Educational Philosophy and Theory, 25(1),1-21. https://doi.org/10.1080/00131857.2020.1811678

Krasnoshchekov, V., Arseniev, D., Rud, V., Switala,F., \& V. Chetiv. (2019). Improving the quality of pre-master training of foreign students in the field of environment. IOP Conference Series: Earth and Environmental Science, 390, 012017. https://doi.org/10.1088/1755-1315/390/1/012017

Lorente, L.M., Arrabal, A.A. \& Pulido-Montes, C., (2020). The Right to Education and ICT during COVID-19: An International Perspective. Sustainability 12(2). https://doi.org/10.3390/su12219091

Merkish, N., (2020). Comprehension of the cultural component of vocabulary as a precondition for successful communication with native speakers. Science for Education Today 10(1), 175-188. 10.15293/2658-6762.2004.11.

Mulcahy, M. D., (2013). "Turning Around the Question of 'Transfer' in Education: Tracing the sociomaterial." Educational Philosophy and Theory 45(12), 276-1289. https://doi.org/10.1080/00131857.2013.763592

Nordmann, A. \& Ripper, A., (2019). Safety and Security - Their Relation and Transformation. In: Reuter C. (eds.), Information Technology for Peace and Security. Springer Vieweg, Wiesbaden. https://doi.org/10.1007/978-3-658-25652-4_16

Mubita, K., (2021). Understanding School Safety and Security: Conceptualization and Definitions. Journal of Lexicography and Terminology 5(1), 76-86. (Online ISSN 2664-0899. Print ISSN 2517-9306).

Peters, M.A., Arndt, S., Tesar, M., Jackson, L., Hung, R., Mika, C. \& A. Gibbons. (2020). "Philosophy of education in a new key." Educational Philosophy and Theory, 21(2), 1-22. https://doi.org/10.1080/00131857.2020.1759194

Pokrovskaia, N.N., Leontyeva, V.L., Ababkova, M.Y., Cappelli, L. \& F. D’Ascenzo. (2021). Digital Communication Tools and Knowledge Creation Processes for Enriched Intellectual Outcome-Experience of Short-Term E-Learning Courses during Pandemic. Future Internet 13(2), 43. https://doi.org/10.3390/fi13020043

Pokrovskaya, N.N. \& Tyulin, A.T., (2021). Psychological Features of the Regulative Mechanisms Emerging in the Digital Space. Technology and Language 2(2), 106-125. https://doi.org/10.48417/technolang.2021.02.11

Soni, V. (2020). Global Impact of E-learning during COVID 19. SSRN. Electronic Journal, 12.10.2139 / ssrn.36

Spenceley, L. (2006). 'Smoke and mirrors': an examination of the concept of professionalism within the FE sector. Research in Post-Compulsory Education, 11(3), 289-302. https://doi.org/10.1080/13596740600916534

Tesar, M. (2020). Towards a Post-Covid-19 'New Normality?': Physical and Social Distancing, the Move to Online and Higher Education." Policy Futures in Education, 18(5), 556-559. https://doi.org/10.1177/1478210320935671 
Valieva, F., Fomina, S. \& Nilova, I., (2021). Distance Learning During the CoronaLockdown: Some Psychological and Pedagogical Aspects. In Knowledge in the Information Society. PCSF 2020, CSIS 2020. Lecture Notes in Networks and Systems, vol. 184, 289-300. https://doi.org/10.1007/978-3-030-65857-1_25

Vorotnikova, V. \& Karlin, S., (2021). Non-linguistic systems as a way to make a password secure but memorable. Technology and Language, 2(1), 98-121. https://doi.org/10.48417/technolang.2021.01.08]

Yang, B. \& C. Huang. (2021). "Turn crisis into opportunity in response to COVID19: experience from a Chinese University and future prospects." Studies in Higher Education, 46(1), 121-132. https://doi.org/10.1080/03075079.2020.1859687

Words: 4851

Characters: $32720(18,18$ standard pages $)$

Assoc. Prof. Ekaterina A. Samorodova, PhD.

French Language Department

Moscow State Institute of International Relations (MGIMO University)

119454, Moscow, Prospekt Vernadskogo, 76

Russia

samorodova.ekaterina.78@mail.ru

Irina G. Belyaeva, PhD.

German Language Department

Moscow State Institute of International Relations (MGIMO University)

119454, Moscow, Prospekt Vernadskogo, 76

Russia

i.beliaeva@inno.mgimo.ru

Assoc. Prof. Daria S. Bylieva, PhD.

Department of Social Science

Peter the Great St.Petersburg Polytechnic University

195251, St.Petersburg, Polytechnicheskaya, 29

Russia

Bylieva_ds@spbstu.ru

Prof. Alfred Nordmann

Institute of Philosophy

Darmstadt Technical University,

64289, Darmstadt, Karolinenplatz 5,

Germany

nordmann@phil.tu-darmstadt.de 